\title{
Research on the Characteristics and Regularity of Evacuation in Railway Tunnel Emergency Rescue Station at High Altitude
}

\author{
Liao Xueling ${ }^{1}$, Li Qi ${ }^{*}$, Min Xiangjie ${ }^{1}$, He Ruiwen ${ }^{1}$, Teng Ruizhi ${ }^{1}$, Zhang Ruihua ${ }^{1}$ \\ ${ }^{1}$ School of Architecture and Urban-Rural Planning, Sichuan Agricultural University, Chengdu, Du Jiangyan, Sichuan, 611830, China
}

\begin{abstract}
With the development of economy, railway construction is gradually expanding to the plateau area, and the number of super-long railway tunnels at high altitude is increasing year by year. Compared with the plain area, due to the influence of hypoxia and panic, there are obvious differences in evacuation rules in plateau environment. In this paper, considering the high altitude environment, panic psychology, people's age and gender and train structure factors, we use the Pathfinder personnel evacuation simulation technology, simulate and analyze evacuation of personnel in emergency rescue stations with different structural parameters. Finally we obtain the characteristics and rules of the evacuation of personnel in emergency rescue stations of high-altitude railway tunnels, and give the suggested design values of structural parameters of emergency rescue stations of high-altitude railway tunnels, so as to provide reference basis for its construction.
\end{abstract}

\section{Introduction}

With the development of China's basic economic construction and the gradual improvement of the railway network, railway tunnels are gradually developing towards higher altitude and longer length. The total length of railway tunnels is increasing year by year, and the number of extra-long railway tunnels $(>20 \mathrm{~km})$ and highaltitude railway tunnels continues to increase. In order to ensure the safety requirements of disaster prevention and rescue for extra-long railway tunnels, it is stipulated in the Design Code for Disaster Prevention and Evacuation Rescue Engineering of Railway Tunnels that at least one emergency rescue station will be set up in the railway tunnel which is longer than $20 \mathrm{~km}$ [1]. Extra-long railway tunnels at high altitude are increasing year by year, the problem of disaster prevention and rescue we face is serious. In addition, under the influence of high-altitude environment and panic psychology, the difficulty of personnel evacuation is greatly increased. If evacuation is improper or evacuation capacity of the emergency rescue station is insufficient (It is embodied in the width and spacing of the cross passage in the emergency rescue station), it may cause inestimable casualties.

\section{Establishment of evacuation model for the emergency rescue station}

A calculation model for evacuation in emergency rescue stations in high-altitude railway tunnels was established by taking a typical unilateral plane-guided emergency rescue station (Figure 1) in Sichuan-Tibet railway as the research object.

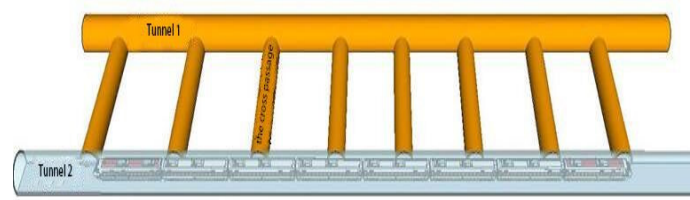

Figure 1. Unilateral horizontal guide emergency rescue station

The basic parameters of evacuation model in the highaltitude railway tunnel emergency rescue station mainly include five aspects, as follows:

\subsection{Train structure data}

The length of each train tourist coach compartment is $28.3 \mathrm{~m}$, the width is $3.0 \mathrm{~m}$ and the width of the tunnel is $7.0 \mathrm{~m}$

\subsection{Train load}

The train is generally 16 carriages, divided into 1 dining car carriage, 3 first-class carriages, 12 second-class carriages, 104 passengers per first-class carriage, 130 passengers per second-class carriage, 28 passengers per dining car carriage, a total of 1,900 passengers.

\subsection{Proportion of train personnel}

According to the statistics of railway personnel travelling ratio, the results are shown in Figure 2 [2].

*Corresponding author's e-mail: 602347502@qq.com. 


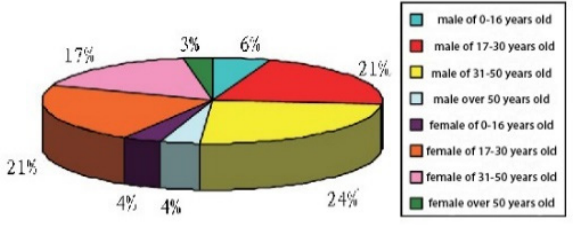

Figure 2 Proportion of railway personnel

\subsection{Evacuation speed}

The plateau environment can directly or indirectly affect various organs and systems of the human body to varying degrees, and these effects are fed back through indicators such as brain function, heart rate and blood oxygen concentration[3], however, when the train running on the plateau has a sudden crisis, the passengers will have different degrees of panic psychology due to the dense personnel on the train and the sealed environment. In the process of evacuation, the panic of pedestrians will be reflected in their behavior [4], which will greatly affect evacuation speed. Since it is difficult for individuals to comply with group norms for evacuation in a panic state, it may lead to increased retention time, secondary trampling, reduced evacuation efficiency and other adverse effects [5], so the impact of panic psychology on evacuation speed cannot be ignored. After comprehensive consideration of the plateau environment and panic psychology, evacuation speed of personnel in emergency rescue stations of high-altitude railway tunnels under the influence of panic psychology is shown in Equation (1), and the specific data are shown in Table 1.

$$
\mathrm{V}=\alpha_{1} \alpha_{2} \mathrm{~V} \text { evacuation speed on the plain }
$$

In the formula: $\alpha_{1}$ the reduction coefficient of evacuation speed under high altitude environment[6]; $\alpha_{2}$ _the increase coefficient of panic psychology on

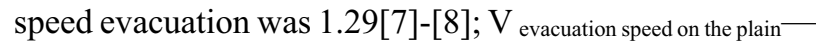
- evacuation speed on the plain: children $0.8 \mathrm{~m} / \mathrm{s}$, adult male $1.2 \mathrm{~m} / \mathrm{s}$, adult female $1.0 \mathrm{~m} / \mathrm{s}$, the elderly $0.72 \mathrm{~m} / \mathrm{s}[9]$.

Table 1 Evacuation speed of emergency rescue stations in high-altitude railway tunnels under the influence of panic psychology

\begin{tabular}{ccr}
\hline & & \\
the altitude $(\mathrm{km})$ & children & adult m \\
\cline { 2 - 3 } & 1.032 & 1.548 \\
1 & 1.004 & 1.505 \\
2 & 0.949 & 1.418 \\
3 & 0.867 & 1.29 \\
4 & 0.761 & 1.122 \\
5 & & \\
& & \\
& & \\
2.5 Structural data of the emergency & rescue \\
station &
\end{tabular}

The platform height of the emergency rescue station is $0.7 \mathrm{~m}$ and the width of the platform is $2.0 \mathrm{~m}$. By changing the width $(1.0 \mathrm{~m}, 1.5 \mathrm{~m}, 2.0 \mathrm{~m}, 2.5 \mathrm{~m})$ and spacing $(50 \mathrm{~m}$, $60 \mathrm{~m}, 70 \mathrm{~m}, 80 \mathrm{~m})$ of the transverse channel, and considering different altitudes $(1 \mathrm{~km}, 2 \mathrm{~km}, 3 \mathrm{~km}, 4 \mathrm{~km}$, $5 \mathrm{~km}), 80$ calculation models are established.

\section{Evacuation characteristics and rules of the emergency rescue station in high- altitude railway tunnel}

Evacuation time under 80 working conditions is obtained through simulation of personnel evacuation, as shown in Table 2.

Table 2 Evacuation time under different working conditions (s)

\begin{tabular}{rrrrrr}
\hline $\begin{array}{c}\text { the } \\
\text { altitude }\end{array}$ & $\begin{array}{l}\text { the spacing/ } \\
\text { the width of } \\
\text { the cross } \\
\text { passage }\end{array}$ & $1.0 \mathrm{~m}$ & $1.5 \mathrm{~m}$ & $2.0 \mathrm{~m}$ & $2.5 \mathrm{~m}$ \\
\hline \multirow{4}{*}{$1 \mathrm{~km}$} & $50 \mathrm{~m}$ & 317.3 & 186.1 & 166.8 & 160.0 \\
& $60 \mathrm{~m}$ & 320.4 & 230.4 & 201.2 & 190.2 \\
& $70 \mathrm{~m}$ & 335.6 & 259.4 & 224.3 & 223.0 \\
& $80 \mathrm{~m}$ & 488.8 & 334.2 & 330.4 & 324.3 \\
\hline
\end{tabular}

Comprehensive evacuation speed

\begin{tabular}{lcc} 
lt male & adult female & the elderly \\
.548 & 1.290 & 0.929 \\
.505 & 1.262 & 0.903 \\
.418 & 1.193 & 0.857 \\
.291 & 1.087 & 0.785 \\
.122 & 0.952 & 0.693 \\
\hline
\end{tabular}

\begin{tabular}{llllll}
\hline \multirow{3}{*}{$2 \mathrm{~km}$} & $50 \mathrm{~m}$ & 307.1 & 178.7 & 160.5 & 162.0 \\
& $60 \mathrm{~m}$ & 312.2 & 238.9 & 214.1 & 168.2 \\
& $70 \mathrm{~m}$ & 343.4 & 235.1 & 213.4 & 210.4 \\
& $80 \mathrm{~m}$ & 550.5 & 341.5 & 340.2 & 335.6 \\
\hline \multirow{3}{*}{$3 \mathrm{~km}$} & $50 \mathrm{~m}$ & 318.5 & 187.5 & 187.2 & 186.7 \\
& $60 \mathrm{~m}$ & 324.9 & 273.5 & 247.7 & 216.5 \\
& $70 \mathrm{~m}$ & 375.6 & 275.7 & 250.3 & 220.2 \\
& $80 \mathrm{~m}$ & 585.4 & 409.0 & 365.3 & 360.6 \\
\hline \multirow{3}{*}{$4 \mathrm{~km}$} & $50 \mathrm{~m}$ & 306.4 & 207.7 & 181.0 & 205.3 \\
& $60 \mathrm{~m}$ & 322.2 & 229.8 & 220.6 & 208.3 \\
& $70 \mathrm{~m}$ & 381.7 & 249.3 & 257.7 & 239.1 \\
& $80 \mathrm{~m}$ & 560.8 & 490.2 & 476.2 & 463.2 \\
\hline \multirow{4}{*}{$5 \mathrm{~km}$} & $50 \mathrm{~m}$ & 343.9 & 309.4 & 225.2 & 178.4 \\
& $60 \mathrm{~m}$ & 351.1 & 341.4 & 270.5 & 236.1 \\
& $70 \mathrm{~m}$ & 438.2 & 344.9 & 278.2 & 271.9 \\
& $80 \mathrm{~m}$ & 631.2 & 563.1 & 446.5 & 425.9 \\
\hline
\end{tabular}

Table 2 shows that:

(1) When the width and spacing of the cross passage remain unchanged, with the altitude rising, evacuation speed slows down due to insufficient oxygen uptake in the plateau environment, which leads to longer evacuation time. When the width of the cross-passage is $2.0 \mathrm{~m}$, the spacing is $60 \mathrm{~m}$ and the altitude is $4 \mathrm{~km}$, evacuation time is $220.6 \mathrm{~s}$; when the altitude is $5 \mathrm{~km}$, evacuation time is $270.5 \mathrm{~s}$.

(2) When altitude and the distance between cross- 
channel is unchanged, the smaller the width of crosschannel is, the longer evacuation time is, and vice versa. When the altitude is $3 \mathrm{~km}$, the spacing between transverse passages is $70 \mathrm{~m}$ and the width is $2.5 \mathrm{~m}$, evacuation time is $250.3 \mathrm{~s}$, and when the width is $2.0 \mathrm{~m}$, evacuation time is $220.2 \mathrm{~s}$

(3) When the altitude and the width of the crosschannel is unchanged, the smaller the cross-channel spacing is, the shorter evacuation time is, and vice versa. When the altitude is $2 \mathrm{~km}$, the width of the cross-passage is $2.5 \mathrm{~m}$ and the spacing is $70 \mathrm{~m}$, evacuation time is $210.4 \mathrm{~s}$ and when the spacing is $60 \mathrm{~m}$, evacuation time is $168.2 \mathrm{~s}$.

\section{Recommended design values for structural parameters of high-altitude railway tunnel emergency rescue station}

At present, the subway standards in Europe, the United States and China [10]-[11] provide that in case of an emergency in a tunnel, it is safe for people to be evacuated within 6 minutes. Considering the influence of smoke exhaust from the emergency rescue station and assuming that people are not threatened by fire within 6 minutes, a conclusion can be drawn from the simulation results, as shown in Table 3 below:

Table 3 Recommended design values for structural parameters of high-altitude railway tunnel emergency rescue station

\begin{tabular}{ccc}
\hline $\begin{array}{c}\text { the } \\
\text { altitude }\end{array}$ & $\begin{array}{c}\text { the spacing of the } \\
\text { cross passage }\end{array}$ & $\begin{array}{c}\text { the width of the cross } \\
\text { passage }\end{array}$ \\
\hline $1 \mathrm{~km}$ & $\leq 80 \mathrm{~m}$ & $\geq 1.0 \mathrm{~m}$ \\
$2 \mathrm{~km}$ & $\leq 80 \mathrm{~m}$ & $\geq 1.0 \mathrm{~m}$ \\
& $=70 \mathrm{~m}$ & $>1.0 \mathrm{~m}$ \\
$3 \mathrm{~km}$ & $<70 \mathrm{~m}$ & $\geq 1.0 \mathrm{~m}$ \\
& $=70 \mathrm{~m}$ & $>1.0 \mathrm{~m}$ \\
$4 \mathrm{~km}$ & $<70 \mathrm{~m}$ & $\geq 1.0 \mathrm{~m}$ \\
& $=70 \mathrm{~m}$ & $>1.0 \mathrm{~m}$ \\
$5 \mathrm{~km}$ & $<70 \mathrm{~m}$ & $\geq 1.0 \mathrm{~m}$ \\
\hline
\end{tabular}

\section{Conclusion}

Through the above research, the main conclusions are as follows:

(1)When the width and spacing of the cross passage remain unchanged, with the altitude rising, evacuation speed will slow down due to insufficient oxygen uptake in the plateau environment, thus leading to longer evacuation time;

(2) When the altitude and the spacing of the cross passage is unchanged, the width of the cross passage is smaller, and evacuation time is longer, and vice versa;

(3) When the altitude and the width of the cross passage are unchanged, the smaller the spacing of the cross passage is, the shorter evacuation time is, and vice versa;

(4) Recommended design values for structural parameters of high-altitude railway tunnel emergency rescue station:

The spacing of cross passage in railway tunnel emergency rescue station shall not be more than $70 \mathrm{~m}$, and the width of cross passage shall not be less than $1.0 \mathrm{~m}$.

\section{Acknowledgments}

Fund Project: National Natural Science Foundation of China (51908387); Sichuan Agricultural University Scientific Research Interest Cultivation Project (2020804)

\section{References}

1. National Railway Administration of the People's Republic of China. Design Specifications for Railway Tunnel Disaster Prevention and Evacuation Rescue Engineering [S]. China Railway Publishing House, 2018.

2. WANG Mingnian, LI Qi, YU Li, et al.Study of personnel property key parameters under fire evacuation in shield railway tunnel[J].The Eighth Chain-Japan Conference on Shield Tunneling, 2015:203-208.

3. Xing Guoquan. Analysis of factors influencing human body function in low-oxygen environment at high altitude [J]. Intelligence, 2014 (26) : 357.

4. Li Yi. Simulation Analysis of evacuation passenger flow in subway station under fire conditions [D]. Southwest Jiaotong University, 2017.

5. Zhu Huagui. Analysis of panic behavior and influencing factors of disaster victims in the context of sudden disaster [J]. University, 2012 (5) : 90-96.

6. Li Qi (2020) RESEARCH ON ESCAPE VELOCITY OF PEOPLE AT HIGH ALTITUDE. In: 2020 International Conference on Wireless Communications and Smart Grid. Qingdao. pp. 107110.

7. Kholshevnikov V V.The study of humanflows and methodology evacuationstandardisation[C].Moscow:MIFS,1999.

8. KholshevnikovVV.Human flows in buildings, structures and on their adjoining territories[C].Doctor of science thesis.Moscow:MISI,1983.

9. PIARC Committee on Road Tunnels. Fire and Smoke Control in Road Tunnels[S]. 2005

10. Ministry of Railways, PRC. TB 10020-2012 Railway Tunnel Disaster Prevention and Rescue Evacuation Project Design Specification [S]. Beijing: China Railway Publishing House, 2012.

11. National Fire Protection Association. NFPA 130:Standard for Fixed Guideway Transit and Passenger Rail Systems[S]. Quincy: NFPA, 2003. 